\section{Energies of Trivalent Cation Impurity-Cation Vacancy Complexes in $\mathrm{KCl}$}

\author{
A. K. Shukla and M. K. Uppal \\ Department of Chemistry, Indian Institute of Technology, \\ Kanpur 208016, India
}

(Z. Naturforsch. 31 a, 219-220 [1976] ; received January 20, 1976)

Interaction energies of six trivalent cation impurity. cation vacancy configurations in $\mathrm{KCl}$ have been evaluated and compared with experimental data.

\section{Introduction}

There have been extensive theoretical and experimental ${ }^{1-8}$ studies on divalent cation (or anion) impurity-cation (or anion) vacancy pairs in alkali halides during the last few decades. The nature of the interaction of trivalent impurity cations, $\mathrm{M}^{3+}$, with cation vacancies in alkali halides is not understood and experimental studies on such systems are limited to a few recent reports on the conductivity, dielectric loss and optical spectra of $\mathrm{M}^{3+}$ doped alkali halides ${ }^{9-12}$. Introduction of $\mathrm{M}^{3+}$ impurity ions into the cation sublattice of $\mathrm{KCl}$ creates two cation vacancies for each $\mathrm{M}^{3+}$ impurity ion introduced. These vacancies can form complexes with the impurity ion differing in their configuration as shown in Figure 1. We have carried out calculations on the energies of association of such complexes in the $\mathrm{KCl}: \mathrm{Pr}^{3+}$ system in the light of the available

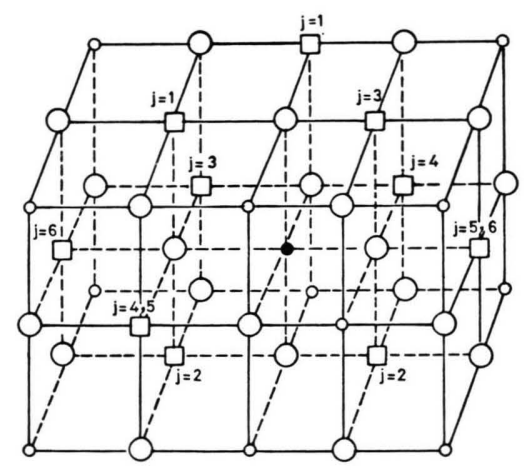

$$
\begin{aligned}
& \text { - Impurity Ion }\left(\mathrm{M}^{3+}\right) \text { ○ Cation } \\
& \square \text { Cation Vacancy } \bigcirc \text { Anion }
\end{aligned}
$$

Fig. 1. $\mathrm{NaCl}$ lattice showing various $\mathrm{M}^{3+}$-cation vacancy complexes indicated by $j=1,2,3,4,5,6$.

* The value of the radius for the $\operatorname{Pr}^{3+}$ ion (1.33 $\AA$ ) was derived from the crystallographic data of Zachariasen ${ }^{16}$ so as to be in conformity with the ionic radii given by Tosi ${ }^{17}$ for $\mathrm{Cl}^{-}(1.63 \AA)$ and $\mathrm{K}^{+}(1.51 \AA)$. experimental data employing the generalised formulation described elsewhere ${ }^{1,2,13}$. It may be noted that theoretical evaluations of various defect parameters such as energies of formation, association and migration of defects in ionic solids employing the Born model of cohesion have met with considerable success $^{1-3,13-15}$ and have led to a better understanding of experimental observations.

\section{Results and Discussion}

By employing ionic radii * of $1.33,1.63$ and $1.51 \AA$ for $\mathrm{Pr}^{3+}, \mathrm{Cl}^{-}$and $\mathrm{K}^{+}$respectively, we have obtained defect parameters for the isolated cation vacancy and $\mathrm{Pr}^{3+}$ impurity ion in the $\mathrm{KCl}$ lattice (Table 1). The results of our calculations on the various $\mathrm{Pr}^{3+}$-cation vacancy associations $(\mathrm{I}-\mathrm{V}$ complexes) in the $\mathrm{KCl}: \mathrm{Pr}^{3+}$ system are shown in Table 2.

Table 1. Parameters for isolated defects in $\mathrm{KCl}$ (Energies in $\mathrm{eV}$ ).

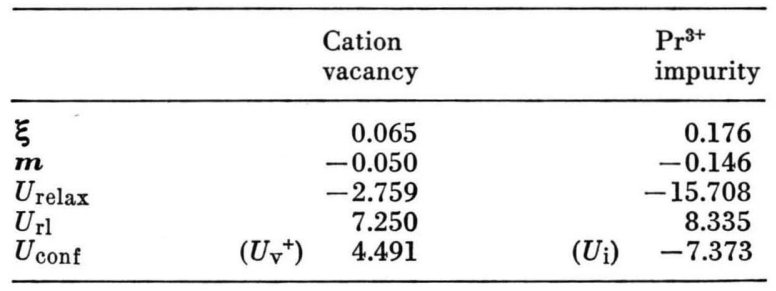

The first of the $\mathrm{I}-\mathrm{V}$ complexes $(j=1)$, where the two cation vacancies are situated close to each other at a distance $\sqrt{2} r_{0}$ ( $r_{0}$ being the interionic distance), is not favoured from energy considerations since vacancies with equal effective charge repel each other. Our calculations show that this type of associated complex cannot exist since it is less stable than the respective isolated defects. In the other five complexes the two charge compensating vacancies are separated by distances of $2 r_{0}(j=2), \sqrt{6} r_{0} \quad(j=3), \sqrt{8} r_{0} \quad(j=4), \sqrt{10} r_{0}$ $(j=5)$ and $4 r_{0}(j=6)$. On multiplying the calculated energy values for these associated states, $E_{j}^{\mathrm{IV}}$, with their respective $Z_{l}$ (total number of equivalent configurations), we obtain the net association energy $\left\langle E_{j}{ }^{\mathrm{IV}}\right\rangle$ for these complexes. If we do so, we find that the fifth associated state $(j=5)$, in which one vacancy is at a nearest neighbour (nn) site and the other at a next-nearest-neighbour (nnn) site relative to the $\mathrm{Pr}^{3+}$ ion, is the most favoured one. This is in conformity with the experimental observations of Radhakrishna et al. ${ }^{11}$. On the basis of our calculations, the order for the different as- 
Table 2. Parameters for $\mathrm{I}-\mathrm{V}$ complexes in $\mathrm{KCl}$ (Energies in $\mathrm{eV}$ ).

\begin{tabular}{|c|c|c|c|c|c|c|c|c|c|c|c|c|}
\hline & \multicolumn{2}{|c|}{$j=1$} & \multicolumn{2}{|c|}{$j=2$} & \multicolumn{2}{|c|}{$j=3$} & \multicolumn{2}{|c|}{$j=4$} & \multicolumn{2}{|c|}{$j=5$} & \multicolumn{2}{|c|}{$j=6$} \\
\hline & $(100)$ & 0.142 & (100) & 0.158 & (100) & 0.162 & (100) & 0.156 & (100) & 0.190 & (100) & 0.179 \\
\hline & (001) & 0.132 & $(010)$ & 0.174 & $(010)$ & 0.161 & $(001)$ & 0.176 & (010) & 0.180 & (010) & 0.168 \\
\hline & $(\overline{1} 00)$ & 0.279 & (001) & 0.177 & (0T0) & 0.170 & (210) & 0.047 & (001) & 0.174 & (300) & 0.059 \\
\hline \multirow{9}{*}{$\xi_{k}$} & $(00 \overline{\mathrm{I}})$ & 0.161 & $(0 \overline{\mathrm{I}} 0)$ & 0.176 & $(200)$ & 0.046 & (111) & 0.076 & $(\overline{1} 00)$ & 0.169 & $(210)$ & 0.051 \\
\hline & (201) & 0.054 & (210) & 0.050 & (120) & 0.045 & & & $(300)$ & 0.049 & & \\
\hline & (111) & 0.136 & (120) & 0.071 & (111) & $0 ., 071$ & & & (120) & 0.054 & & \\
\hline & (102) & 0.038 & (111) & 0.042 & (11I) & 0.084 & & & & & & \\
\hline & (1IIl) & 0.061 & & & & & & & & & & \\
\hline & (100) & -0.130 & (100) & -0.118 & (100) & -0.131 & (100) & -0.122 & (100) & -0.161 & (100) & -0.148 \\
\hline & $(001)$ & -0.144 & $(010)$ & -0.134 & (010) & -0.162 & (001) & -0.184 & (010) & -0.159 & (010) & -0.143 \\
\hline & $(\overline{1} 00)$ & -0.161 & (001) & -0.187 & (0I0) & -0.153 & (210) & -0.045 & (001) & -0.156 & (300) & -0.053 \\
\hline & (00I) & -0.151 & (0I0) & -0.180 & (200) & -0.031 & (111) & -0.049 & (I00) & -0.149 & (210) & -0.046 \\
\hline \multirow[t]{4}{*}{$\boldsymbol{m}_{\mathrm{k}}$} & (201) & -0.050 & (210) & -0.048 & (120) & -0.048 & & & $(300)$ & -0.050 & & \\
\hline & (111) & -0.089 & (120) & -0.047 & (111) & -0.044 & & & (I20) & -0.046 & & \\
\hline & (102) & -0.041 & (111) & -0.051 & $(11 \bar{I})$ & -0.047 & & & & & & \\
\hline & (111) & -0.047 & & & & & & & & & & \\
\hline$U_{\text {relax }}$ & \multicolumn{2}{|c|}{-12.087} & \multicolumn{2}{|c|}{-11.742} & \multicolumn{2}{|c|}{-11.088} & \multicolumn{2}{|c|}{-10.830} & \multicolumn{2}{|c|}{-13.100} & \multicolumn{2}{|c|}{-14.949} \\
\hline$U_{\mathrm{rl}}$ & \multicolumn{2}{|c|}{13.749} & \multicolumn{2}{|c|}{12.676} & \multicolumn{2}{|c|}{12.379} & \multirow{2}{*}{\multicolumn{2}{|c|}{$\begin{array}{r}12.006 \\
1.176\end{array}$}} & \multicolumn{2}{|c|}{13.607} & \multicolumn{2}{|c|}{15.077} \\
\hline$U_{\text {conf }}^{\mathrm{IV}(\mathrm{f})}$ & \multicolumn{2}{|c|}{1.662} & \multirow{2}{*}{\multicolumn{2}{|c|}{$\begin{array}{l}0.934 \\
0.675\end{array}$}} & \multirow{2}{*}{\multicolumn{2}{|c|}{$\begin{array}{l}1.291 \\
0.318\end{array}$}} & & & \multirow{2}{*}{\multicolumn{2}{|c|}{0.507}} & \multicolumn{2}{|c|}{0.128} \\
\hline$E_{j} \mathrm{IV}\left(\mathrm{a}_{i}\right.$ & \multirow{2}{*}{\multicolumn{2}{|c|}{$\begin{array}{l}-0.053 \\
16\end{array}$}} & & & & & \multicolumn{2}{|c|}{0.433} & & & & 1.481 \\
\hline & & & \multicolumn{2}{|r|}{6} & \multicolumn{2}{|c|}{12} & \multicolumn{2}{|c|}{6} & \multirow{2}{*}{\multicolumn{2}{|c|}{$\begin{array}{l}8 \\
8.816\end{array}$}} & & 3 \\
\hline$\left\langle E_{j} \mathrm{IV}\right\rangle$ & - & 0.848 & & 4.050 & & 3.816 & & 2.598 & & & & \\
\hline
\end{tabular}

(a) The association energies are evaluated as follows: $E_{j}{ }^{\mathrm{IV}}=2 U_{\mathrm{v}}{ }^{+}+U_{\mathrm{i}}-U_{\text {conf }}^{\mathrm{rv}(\mathrm{j})}$.

sociated states works out to be fifth $>$ sixth $>$ second $>$ third $>$ fourth. It is noteworthy that Radhakrishna et al. ${ }^{11}$ have analysed their experimental data in the light of the fourth, fifth and sixth associated state of these $\mathrm{I}-\mathrm{V}$ complexes.

1 A. K. Shukla, S. Ramdas, and C. N. R. Rao, J. Chem. Soc. Faraday Trans. II, 69, 207 [1973].

2 S. Ramdas, A. K. Shukla, and C. N. R. Rao, Chem. Phys. Letts. 16, 14 [1972].

3 P. K. Swaminathan, A. K. Shukla, and C. N. R. Rao, Chem. Phys. Letts. 23, 318 [1973].

4 S. Ramdas and C. N. R. Rao, Crystal Latice Defects, [1975].

5 J. H. Crawford, Jr., J. Phys. Chem. Solids 31, 399 [1970].

6 G. D. Watkins, Phys. Rev. 113, 79 [1959].

7 S. C. Jain, A. V. R. Warrier, and S. K. Agarwal, Chem. Phys. Letters 14, 211 [1972].

8 S. C. Jain, D. Polley, and R. Singh, J. Phys. C, 5, 1307 [1972].

\section{Acknowledgements}

The authors are thankful to Professor C. N. R. Rao for suggesting the problem and helpful guidance and to the Air Force Office of Scientific Research (71-2138) for support of this research.

9 B. Prakash and C. N. R. Rao, Indian J. Chem. 12, 607 [1974].

10 S. Radhakrishna and A. M. Karguppikar, J. Phys. Chem. Solids 34, 1497 [1973].

11 S. Radhakrishna and B. D. Sharma, Phys. Rev. B 9, 2073 [1974].

12 M. Hartmanová, E. Mariani, and M. Lébl, J. Phys. C 7, L 137 [1974].

13 M. P. Tosi and M. Doyama, Phys. Rev. 151, 642 [1966].

14 S. Ramdas, A. K. Shukla, and C. N. R. Rao, Phys. Rev. B 8, 2975 [1973].

15 A. K. Shukla, S. Ramdas, and C. N. R. Rao, J. Solid State Chem. 8, 120 [1973].

16 W. H. Zachariasen, Acta. Cryst. 1, 265 [1948].

17 M. P. Tosi, Solid State Phys. 16, 1 [1964]. 